\title{
KONTRIBUSI MẠ̣FŪẒ AL-TARMASĪ DALAM PENGKAJIAN HADIS DI INDONESIA
}

\author{
Ahmad Faisal \\ Guru Pesantren Ar-Raudhatul Hasanah Medan \\ Jl. Setia Budi, Simpang Selayang, Medan Tuntungan, 20135, Sumatera Utara, Indonesia \\ Email: ahmadfaisal@yahoo.com
}

\begin{abstract}
Modern Hadīs experts are still very minimal, even there are still many muhaddis figures who are not yet known by the public. One of them was Shaykh Muhammad Mahfüz ibn Abdullāh ibn Abd alMannān al-Tarmasī al-Jāwī al-Makkī al-Syāfi ì. Shaykh Muhammad Mahfuz compiled the book of Jurisprudence and Proposals, Hadīs and also al-Qirā'at. The contribution of Mahfüz al-Tarmasī's thoughts in the study of Hadìs in Indonesia can be seen in the book, first; Al-Minhah al-Khairiyyah. Second, Manhaj Żawi al-Nazar fì Syarh Manzümati 'Ilm al- 'Aśar. Third, Transmission of Sanad in the book entitled Kifāyatu al-Mustafìd fìmā 'alā min al-Asānīd by the work of Muhammad Yāsin alFānānī. Mahfuz al-Tarmasī's work entitled Manhaj Żawī al-Nazar fì Syarh Manzumati 'Ilm al-'Asiar is a book that is used as a reference in many universities such as Egypt, Morocco, Mecca and Indonesia. This one work is the explaination book from the great work of the world Hadīs scholars, namely Alfiyyah al-Suyūtì who discusses the science of Hadīs. The difficulty in understanding the nazm-nazm contained in the work of al-Suyūtīi, makes Mahfuz al-Tarmasī challenged and then agrees with it with the intention to be more easily understood and understood by students and lovers of Hadīs knowledge in general.
\end{abstract}

Keywords: The Contribution, al-Minhah al-Khairiyyah, Manhaj Żawī al-Nazar, Kifāyatu al-Mustafìd

\begin{abstract}
Abstrak
Pakar hadis modern masih sangat minim sekali, bahkan masih banyak tokoh-tokoh muhaddis yang belum dikenal oleh masyarakat. Salah satunya adalah Syaikh Muhammad Mahfüz ibn Abdullāh ibn Abd al-Mannān al-Tarmasī al-Jāwī al-Makkī al-Syāfi ‘ì. Syaikh Muhammad Mah̆uz al-Tarmasī telah menyusun kitab fikih dan ușūl, hadis dan juga al-Qirā'at. Kontribusi pemikiran Mahfüz al-Tarmasī dalam pengkajian Hadis di Indonesia dapat dilihat dalam kitab, pertama; Al-Minhah al-Khairiyyah. kedua, Manhaj Żawī al-Nazar fì Syarh Manzūmati 'Ilm al- 'Aśar. Ketiga, Transmisi Sanad dalam kitab yang berjudul Kifāyatu al-Mustafíd fìmā 'alā min al-Asānīd karya Muhammad Yāsin al-Fādānī.

Karya Mahfuz al-Tarmas̄̄ yang berjudul Manhaj Żawī al-Nazar fì Syarh Manzumati 'Ilm al-'Aśar merupakan karya yang dijadikan referensi di banyak Universitas seperti Mesir, Maroko, Mekah dan Indonesia. Karya yang satu ini merupakan kitab syarah dari karya besar ulama hadis dunia, yakni Alfiyyah al-Suyūțī yang membahas tentang ilmu hadis. Kesulitan dalam memahami nazm-nazm yang terdapat dalam karya al-Suyūț̄i, menjadikan Mahfuz al-Tarmasī tertantang untuk kemudian mensyarahnya dengan maksud agar lebih mudah dipahami dan dimengerti para pelajar dan pecinta ilmu hadis pada umumnya.
\end{abstract}

Kata Kunci: Kontribusi, al-Minḥah al-Khairiyyah, Manhaj Żawī al-Nazar, Kifāyatu al-Mustafìd

\section{Pendahuluan}

Ilmu Hadis adalah kajian yang tertinggal di Indonesia jika dibandingkan dengan ilmu ke-Islaman lainnya seperti tafsir, ilmu fikih dan ilmu tasawuf. Hal ini dapat dibuktikan dengan minimnya pakar hadis di negeri ini dan sedikitnya literatur yang mengulasnya. Oleh sebab itu ada kesan bahwa ilmu hadis merupakan kajian 
yang tercecer di tanah yang jumlah penduduk Muslimnya terbesar di dunia.

Kajian hadis di Indonesia sudah dimulai pada abad ke-17 Masehi. Hal ini dibuktikan dengan kitab karangan Nur adDīn al-Ranirī yaitu Hidāyatu al-Habīb fì atTarghīb wa at-Tarhīb (Petunjuk kekasih dalam hal yang menggembirakan dan menakutkan). Kitab hadis ini berisi 831 hadis yang berbahasa Arab dan diterjemahkan ke dalam bahasa Melayu. Kitab ini ditulis pada tahun $1045 \mathrm{H} / 1635$ M. Saat ini kitab ini dicetak dengan judul al-Fawā'id al-Bahiya fì al-Ahādisं anNabawiyyah dalam Hāsyiah Jam'ul Fawāid, karya Daud ibn Abdillah alFatani. $^{1}$

Menurut al-Ranirī, penerapan syariat tidak dapat ditingkatkan tanpa pengetahuan lebih mendalam mengenai hadis Nabi saw. Karena itu, dia mengumpulkan dalam karyanya Hidāyat alHabīb fì al-Targhīb wa al-Tarhīb sejumlah hadis yang diterjemahkannya dari bahasa Arab ke bahasa Melayu agar penduduk Muslim mampu memahaminya secara benar. Karya ini merupakan rintisan dalam bidang hadis di Nusantara. ${ }^{2}$

\footnotetext{
${ }^{1}$ Matsuki \& M Ishom el-Saha, Intelektualisme Pesantren Potret Tokoh dan Cakrawala Pemikiran di Era Pertumbuhan Pesantren, juz I (Jakarta: Diva Pustaka, 2003), 66.

${ }^{2}$ Azyumardi Azra, Jaringan Ulama Timur Tengah dan Kepulauan Nusantara Abad XVII \& XVIII (t.t.: t.p., t.th.), 226.
}

\section{Riwayat Hidup Muḥammad Maḥfuz al-} Tarmasī

Nama lengkapnya adalah Syaikh Muḥammad Maḥfūz ibn Abdullāh ibn Abd al-Mannān al-Tarmasī al-Jāwī al-Makkī alSyāfi‘'̄i. Lahir di Termas di salah satu perkampungan Jawa Tengah di kota Solo pada tanggal 12 Jumādi al-Ula $1285 \mathrm{H}$. Pada saat itu ayahnya bermukim di Mekkah. Beliau di usia muda sudah hafal Alquran, kemudian belajar ilmu dasar fiqih dari beberapa ulama Jawa. ${ }^{3}$

Berkenaan dengan nama al-Tarmas̄̄ sebagai penisbahan hubungan keluarga, daerah Termas merupakan asal kelahirannya. Dalam hal ini terdapat perbedaan pendapat. Pertama, dalam karya Abdurrahman yang berjudul Dari Haramain ke Nusantara menyingkat nama panjang ulama hadis Nusantara ini dengan nama Maḥfūz at-Tismisī. ${ }^{4}$ Kedua, dalam karya Azyumardi Azra yaitu Jaringan Ulama Timur Tengah menuliskan nama ulama yang memiliki tidak kurang dari 20 karya ini dengan nama al-Tarmisī dan alTermasi. Ketiga, karya Ali Mustafa Yaqub

\footnotetext{
${ }^{3}$ Muhammad Maḥfūż ibn Abdillah Muhammad Maḥfūż, Hāsyiyatu Al-Tarmasī aMusamma al-Manhal al-'Amīm bi Hāsyiyati alManhaj al-Qawīm wa Mauhibatu ż̄ al-Faḍl 'ala Syarhi al-Allāmah Ibnu Hajar (Jedah: Dār alManhal, 2011), 11.

${ }^{4}$ Nama at-Tismisī juga tertulis di penerbit Dār al-Fikr ketika menerbitkan kitab hadis karya ulama asal Tremas ini, yang berjudul Manhaj Zawi an-Naẓr.
} 
yaitu Islam Masa Kini, ${ }^{5}$ tertulis dalam bukunya dengan nama al-Tirmasī. Dalam karya Maḥfūz al-Tarmasī yang berjudul alKhil'ah al-Fikriyyah Syarh al-Minhah alKhairiyyah dan Hāsyiat al-Tarmasī yang dinamai al-Manhal al-'Amīm bi Hāsyiati al-Manhaj al-Qawìm wa Mauhibata ż̄i alFaḍl 'alā Syarh al-'Allāmah ibn Hajar Muqaddimah Bāfaḍl dijelaskan cara baca namanya, yakni dengan men-fathah-kan $t \bar{a}$ ' dan mim serta men-sukun-kan $r \bar{a}$,', sehingga dibaca al-Tarmasī. ${ }^{6}$

Pada tahun $1291 \mathrm{H}$, Syaikh Abdullah (sang Ayah) memanggilnya untuk belajar di Mekah, kemudian berangkatlah beliau untuk menemui sang ayah dan bermukim di Makkah untuk mempelajari beberapa kitab kepada sang Ayah. Selanjutnya Muḥammad Maḥfūz alTarmasī kembali ke Jawa dan berguru kepada Syekh Ṣāliḥ ibn Umar al-Samān̄̄ di daerah Semarang untuk mengkaji beberapa kitab di pesantrennya. ${ }^{7}$

Pada kesempatan berikutnya, Syaikh Muhammad Maḥfūz al-Tarmasī kembali ke Makkah guna menimba ilmu. Di sanalah beliau mengambil berbagai disiplin ilmu dari para ulama, diantaranya ialah as-

${ }^{5}$ Ali Mustafa Yaqub, Islam Masa Kini, (Jakarta: Pustaka Firdaus, 2001), 37.

${ }^{6}$ Muhammad Maḥfūż ibn Abdillah AlTarmas̄̄, Hāsyiyatu At-Tarmas̄̄ a-Musamma alManhal al-'Amīm bi Hāsyiyati al-Manhaj al-Qawìm wa Mauhibatu ż̄ al-Faḍl 'ala Syarḥi al-Allāmah Ibnu Hajar (Jedah: Dār al-Manhal, 2011), 11.

${ }^{7}$ Al-Tarmasī, Hāsyiyatu, 11.
Sayyid Abi Bakr Muhammad Syațā alMakkī, yang merupakan guru dalam bidang periwayatan hadis. $^{8}$ Maḥfūz al-Tarmas̄̄ juga mengkaji beberapa kitab hadis dan muṣtalah-nya dari as-Sayyid Husain bin Muhammad al-Habsyi al-Makki. Beliau juga menimba ilmu hadis kepada Syaikh Muhammad Sa‘̄id Babașīl, serta mempelajari ilmu qirā'at 14 dari Syekh Muḥammad al-Syarbin̄̄ al-Dimyāṭ̂̄. ${ }^{9}$

Beliau memang serius dan bersungguh-sungguh dalam menimba ilmu, hingga terlihat kepandaiannya dalam bidang hadis, menguasai fikih dan uṣull-nya, serta ilmu qirā'at. Sehingga para guru Beliau memberikan izin untuk mengajar. ${ }^{10}$

Maḥfūz al-Tarmasī berguru kepada beberapa ulama yang terkenal di masanya. Di antara guru-guru al-Tarmasi adalah: ${ }^{11}$

1. Syaikh Muḥammad al-Mansyāwī. Ulama ahli qirā'ah sab'ah ini belajar tartīl Alquran menurut qirā'ah Imam Așīm. Ia datang ke Makkah pada tahun $1260 \mathrm{H}$, ia giat menghadiri halaqah Syaikh 'Uṡmān al-Dimyāṭi. Syaikh Maḥfūz alTarmasī mengkhatamkan dua kitab

\footnotetext{
${ }^{8}$ Al-Tarmasī, Hāsyiyatu, 11.

${ }^{9}$ Al-Tarmas̄i, Hāsyiyatu, 12.

${ }^{10}$ Muhammad Maḥfūż ibn Abdillah, Kifāyatu al-Mustafid limā 'Alā min al-Asānid (Saudi: Dār alBasya'iri al-Islāmiyyah, t.th.), 7-8. Lihat juga Abd al-Fattāh Sayyid al-Ajamī al-Marșafi, Hidāyatu alQārī ilā Tajwìd Kalām al-Bārī, juz II (al-Madīnatu al-Munawwarah: Maktabah Tibah, t.th.), 803.

${ }^{11}$ El-Saha, Intelektualisme, juz II, 105.
} 
yaitu, Al-Qur'ān Qirā'atu Așìm fì Riwāyati al-Khalaf bima Tayassara min al-Tajwìd dan Syarh al-Allämah Ibnu al-Qāsih 'ala al-Syātibiyyah. Ia wafat di Mekah pada tahun 1321 $\mathrm{H}^{12}$

2. Umar al-Barakāt ibn Aḥmad asySyāmī al-Biqā̄ī al-Azharī al-Makkī al-Syāfi‘ 'ī dilahirkan di Biqā’ pada tahun $1245 \mathrm{H}$. Beliau tumbuh dan berkembang di kampung itu kemudian berangkat ke Damaskus dan belajar beberapa kitab ilmu agama. Kemudian pindah ke Mesir dan belajar di Universitas al-Azhar. Ia menetap di Mesir 15 tahun. Lalu datang ke Makkah pada taun 1276 $\mathrm{H}$, dan mulai mengajar, banyak murid yang mengikuti halaqahnya. Ulama besar asli Syam yang juga murid dari Syekh Ibrahim al-Bajurī, Syaikh Mậūu al-Tarmasī belajar qira'ah kitab Syuzūr al-Żahab. ${ }^{13}$

3. Al-Syaikh Muștafa ibn Muhammad ibn Sulaimān al-'Afîfĩ al-Makkī alSyafi'ī. Dilahirkan di kota 'Afíf yang terdapat di Mesir. Menghafal Alquran dan sangat bak hafalannya, banyak hafal matan kitab-kitab ilmu

12، Abd al-Raḥmān ibn 'Abd al-Rahīm alMu'allimī, A lām al-Makkiyyīn min al-Qarn at-Tāsi ' ila Qarni al-Rābi' 'Asyar al-Hijrī (Makkah: Mu'assasah al-Furqān li Turāỉ al-Islāmī, 2000), Juz II, 926-927.

${ }^{13} \mathrm{Ibn}$ Abdillah, Kifāyatu, 8. agama dan memperlihatkannya kepada masyāyikh al-Azhar. Ulama yang terkenal dengan ilmu Gramatika Arab dan ilmu Usul Fikih. Maḥfuẓ al-Tarmasī mengkhatamkan dua kitab, yaitu: Syarh al-Mahallī. 'ala Jawāmi' alJawāmi ' dan al-Mughni al-Labib.

4. Al-Habīb Husein ibn Muḥammad ibn Husein al-Habasyī al-Syāfí ${ }^{\prime} \overline{1}$. Ulama yang sangat terkenal dengan zuhudnya. Maḥfuz al-Tarmasī mengkhatamkan dua kitab hadis utama yaitu Sahịh al-Bukhārō dan Sahịh Muslim.

5. Muhammad Sa`īd Babṣil alHaḍramī. Ulama pakar ilmu fikih. Ia juga menjabat sebagai Mufti Syāfíiyyah kota Mekkah saat ini. Maḥfuz al-Tarmasī belajar dua kitab: Syarh 'Uqud al-Yaman dan Syifä'un lil Qaḍ̄ Iyāḍ.

6. Muhammad al-Syarbinī al-Dimyāțī. Ulama pakar fikih dan qirä'ah yang berasal dari kota Dimyāt, Mesir dan bermukim di Mekah ini, Syeikh Maḥfuz al-Tarmasī mengkhatamkan beberapa kitab, antara lain: Syarh Ibn al-Qais 'ala al-Syatibiyyah, Syarh ad-Durar al-Mud̄ì'ah, Tibyān al-Nasyri fi al-Qira'ah al-Asyri, Raud al-Nazīir li al-Mutawalli, 
Itkhaf al-Basarī fì Qirā'at al-Qur'an al-Arba'ata 'Asyar li ibni Battak.

7. Al-Ṣāliḥ al-Musnid Muḥammad Amīn ibn Ahmad Rị̣wān alMadinī. Ulama terkemuka di kota Madinah pada zamannya, Maḥfūz al-Tarmasī mengkhatamkan dan mengambil ijazah beberapa kitab, antara lain: Al-Dalā'il al-Khairāt, al-Ah̆zāb, al-Burdah, al-Auliyat alAljuni, al-Mutawalli, al-Muwatta' $l i$ Imām Mālik ibn Anas.

8. Abu Bakar ibn Muhammad Zain alAbidīn Syațā. Lahir di Mekah tahun $1226 \mathrm{H}$. Ulama yang mendapat julukan Syaikh al-Masyayikh atau guru besarnya para guru besar. Maḥfūz al-Tarmasī belajar ilmu Syari'ah, ilmu Adab, ilmu Usul dan lain sebagainya.

9. Al-Sayyid Ahmad al-Zawāwī alMakkī al-Mālikī. Lahir di Mekah pada tahun $1262 \mathrm{H}$, hafal Alquran dan matan-matan (teks) bebeapa kitab dari berbagai keilmuan, ia giat menuntut ilmu. Syaikh Maḥfūz alTarmasī belajar ilmu darinya yaitu belajar kitab Syarh 'Uqūd al-Jumān, sebagian kitab al-Syifā karya Qāộ̄ 'Iyāḍ.

10. Muhammad Sāliḥ ibn 'Umar alSamāranī yang dikenal dengan Syaikh Saleh Darat Semarang.
Maḥfūẓ al-Tarmasī hadir di halaqahnya dalam pembelajaran Tafsìr al-Jalālain sampai tamat selama dua kali, Syarah asySyarqāwì 'ala al-Hikam, Wașilat atTullāb, Syarah al-Mardīn̄ fì alFalak. $^{14}$

11. Ayah al-Tarmasi yang bernama asySyaikh Abdullah ibn 'Abd alMannān.

Setelah guru-gurunya memberikan ijazah dalam ilmu-ilmu 'aqlī (ilmu-ilmu ușūl fikih, mantiq dan juga ilmu-ilmu naqli seperti tafsir, hadis) dan mengizinkannya mengajar di halaqah Masjidil Haram. Halaqah keilmuannya terletak di Bab Safa, maka dengan keilmuannya yang luas, dalam waktu yang singkat, beliau sudah dikenal sebagai guru berpengaruh di daerahnya masing-masing. Di antara murid-murid Maḥ̂uz al-Tarmasī yaitu: ${ }^{15}$

1. 'Alī ibn Abdullah ibn Muhammad Arsyad ibn Abdillāh al-Banjarī (Banjamasin Kalimantan Selatan) al-Andūnis̄̄ al-Makk̄̄ al-Syāfí‘̄ì. Beliau dilahirkan di Makkah pada tahun 1285 H. Melewati masa kecil dan tumbuh berkembang di Mekah. Ia belajar kepada Syaikh

${ }^{14}$ Ibn Abdillah, Kifāyatu, 7.

${ }^{15}$ Abdurrahman Mas'ud, Dari Haramain ke Nusantara, Jejak Intelektual Arsitek Pesantren (Jakarta: Kencana Media Group, 2006), 179-180. 
Muḥammad Maḥfūẓ al-Tarmas̄̄ dalam kajian fikih dan Nahwu.

2. Muhammad Dimyāṭ̂̄ al-Tarmasī yang merupakan adik kandung Maḥfūz al-Tarmasī.

3. 'Umar ibn Abī Bakar ibn Abdullah ibn Umar ibn Alī ibn Muhammad al-Haḍramī. Ia dilahirkan di Hadramaut Yaman pada tahun 1270 H. Sejak kecil sudah menghafal Alquran dan berlayar bersama ayahnya ke Haramain (Mekah dan Madinah).

4. Al-Muḥaddis Ahmad ibn Abdillāh ibn Muḥammad Syihāb ad-Dīn adDimasyq̄̄, al-Muqri' al-Muhaddis̀. Ia dilahirkan di Damaskus pada tahun $1287 \mathrm{H}$.

5. Al-Ḥāfiz Muḥammad Habīb ibn Abdillāh ibn Aḥmad al-Jinkī alSyanqit̄̄ al-Malikī. Ia dilahirkan di Syanggit. Mauritania pada tahun 1295 H. Ia belajar kepada ulama terbaik di daerahnya, seperti Syaikh Muhammad Amin al-Jinki.

6. Muhammad Bāqir al-Jāwī al-Marikī, dilahirkan pada tahun $1305 \mathrm{H}$.

7. Kiyai Bāqir ibn Muhammad Nūr bin Fāọil ibn Ibrāhīm al-Jokjāwī alAndūnisī al-Makkī. Lahir di Jogyakarta pada tahun $1305 \mathrm{H}$. Kemudian berlayar ke Mekah dan tumbuh kembang di sana giat belajar dari pelbagai ulama terkemuka di antaranya Syaikh al-Tarmasī.

8. Muhammad 'Abd al-Bāqī ibn 'Alī ibn Muḥammad al-Ayūbī alLaknawī. Ia dilahirkan di Lucknow India pada tahun $1286 \mathrm{H}$. Ia Hijrah ke Haramain tahun $1322 \mathrm{H}$ dan belajar dari ulama-ulama terkemuka di antaranya Syaikh al-Tarmasī.

9. Syaikh Sa'adullah al-Maimanī, seorang mufti dari Bombay India.

10. Syaikh Umar bin Hamdan, seorang yang kemudian dikenal juga sebagai ahli hadis dari Haramain.

11. Kiyai Hasyim Asy'ari al-Jumban̄̄ al-Syafi'‘̄. Ia lahir di desa Jombang Jawa Timur pada tahun $1282 \mathrm{H}$, menghafal Alquran dan belajar fikih, nahwu, șaraf dari Syaikh Khalil ibn 'Abdullah al-Bankalān̄̄. Kemudian ia berlayar ke Mekah Mukarramah dan menetap disana selama 6 tahun. Di Mekah ia bertemu dengan Syaikh al-Tarmasī dan sering belajar dengannya karena beliau merupakan rujukan para ulama di Mekah pada saat itu. Kemudian ia kembali ke kampung halaman di Jombang pada tahun 1314 H. Kemudian ia mulai mengajar di pondok pesantren yang didirikan oleh ayahnya. Banyak para ulama dari berbagai daerah 
bedatangan untuk belajar kepadanya. Kiyai Hasyim Asy'ari kemudian mendirikan organisasi kemasyarakatan dengan nama Nahdatul Ulama, dan pada tahap awal ia menjabat sebagai ketuanya. Ia wafat di Jombang Jawa Timur pada tahun 1366 H. (1871-1947).

12. Syaikh al-Muhaddis 'Uma ibn Hamdan ibn 'Umar al-Maḥrūsī alMadanī al-Makkī. Ia dilahirkan di Tunisia pada tahun $1291 \mathrm{H}$. Ia belajar Alquran dan ilmu-ilmu dasar para ulama di daerahnya. Ia belayar ke tanah Hijaz pada tahun $1304 \mathrm{H}$. Di antara guru-gurunya yang memberikan ijazah kepadanya adalah Syaikh Muḥammad Maḥfūz al-Tarmasī. Ijazah yang diberikan dengan tulisan Syaikh Mạ̣fūz alTarmasī dalam kitab Syarh Alfiyyāt al-Suyūṭ̄, yang tertanggal 24 Zulhijjah tahun $1337 \mathrm{H}$. Ia wafat pada tahun $1368 \mathrm{H}$.

13. Kiyai Ihsan ibn Abdillah ibn Muhammad Șāliḥ ibn Abd arRaḥmān al-Jampasī. Ia belajar kepada Syaikh Maḥfūẓ a-Tarmas̄̄

14. KH. Wahab Hasbullah dari Jombang (1888-1971).

15. KH. R. Asnawi Kudus.

16. Mu'ammar bin Kiyai Baidawi dari Lasem.
17. Ma'sum bin Muhammad Lasem.

Demikianlah selayang-pandang guru-guru dan murid-murid Maḥfūz alTarmasī. Setelah bermukim dan mengajarkan ilmu di Mekah selama kurang lebih empat puluh dua tahun. Beliau menghembuskan nafas akhir pada Ahad malam Senin, menjelang azan magrib, diawal bulan Rajab tahun $1338 \mathrm{H}$ bertepatan dengan tahun $1920 \mathrm{M}$, Ia dimakamkan di Ma'lāh Makkah alMukarramah.

\section{Karya-Karya Mụ̣ammad Maḥfuz al-Tarmasī}

Syaikh Muḥammad Maḥfuz alTarmas̄̄ termasuk salah seorang ulama nusantara yang banyak menghasilkan karangan dalam bahasa Arab seperti halnya ulama-ulama nusantara lainnya yang bermukim di Mekah, seperti Syaikh Nawawī al-Bantan̄̄, Syaikh Ahmad Khatib Minangkabau dan Syaikh Abdul Hamid Kudus.

Maḥfuz al-Tarmasī telah menyusun beberapa kitab di berbagai bidang ilmu yang menunjukkan kepada keistimewaan, keunggulan dan keluasan ilmunya. Beliau telah menyusun kitab Fikih dan Ușūl, Hadis dan juga al-Qirā'at. Di antara karya-karya beliau adalah :

1. Is 'äfu al-Mațāli' bi Syarḥi al-Badr al-Lāmi ‘ Naẓm Jam 'u al-Jawāmi ‘ 
2. Insyirāh al-Fu'ād fì Qirā'ati alImām Hamzah.

3. Al-Badru al-Mun̄̄r fì Qirā'ati alImām ibn Kas̀ìr.

4. Bughyatu al-Azkiyā'i fì al-Bahsis an Karāmāt al-Auliyā'.

5. Ta'mìm al-Manāfi' Biqirā'ati alImām Nāfi .

6. Tanwīr al-Ṣadr fì Qirā'ati al-Imām $A b \bar{\imath}$ 'Amrū.

7. Tahyi'atu al-Fikar bi Syarh Alfiyati as-Siyar li al-'Irāqū rahimahullāh.

8. Śsulāsiyyatu al-Bukhārī.

9. Al-Siqāyatu al-Mardiyyah fì Asāmī Kutub Aṣhābina al-Syāfi 'iyyah.

10. 'Ināyatu al-Muftaqir fimā Yata' 'allaqu bisayyidina al-Khidr.

11. Ghaniyyatu al-Ṭalabah bisyarh Nuzum aț-Ṭayibah fì al-Qira'āt al'Asyriyyah.

12. Fath al-Khaibar bi Syarh Miftāh asSiyar.

13. Al-Fawā'id al-Tarmasiyyah fì Asānìd al-Qirā 'āt al- 'Asyriyyah.

14. Kifāyatu al-Mustafìd fìmā 'alā min al-Asānīd.

15. Al-Minhah al-Khairiyyah fì Arba'īna Hadìsan min Ahạdīisi Khair al-Bariyyah.

16. Al-Khil'atu al-Fikriyyah Syarh alMihnatu al-Khairiyyah.

17. Manhaj Żawī al-Naẓar fì Syarḥ Manẓumati 'Ilm al-'Asiar.
18. Mauhibah ż̀̄ al-Fậl Hāsyiyati 'Ala Syarh Mukhtaṣar Bāfạil.

19. Nail al-Ma'mūl bi Hāsyiati Ghayat al-Wușūl fì 'ilm al- 'Ușūl. ${ }^{16}$

Sebagian besar karya itu telah dicetak dan tersebar di seantero dunia Islam. Sebagian karyanya itu dapat dengan mudah ditemukan di Toko Kitab Mustafa Bab al-Halabi yang terletak di belakang Masjid al-Azhar Kairo Mesir.

\section{Kontribusi Pemikiran Muhammad Maḥfuẓ al-Tarmasī terhadap Kajian Hadis di Indonesia}

Syaikh Muḥammad Maḥfūẓ alTarmasī, ketika berada di Mekah sempat mengajarkan ilmunya kepada Syaikh Hasyim Asy'ari, seorang Kiai yang dianggap paling alim di Jawa pada pertengahan abad ke-20. Maḥfuz alTarmasī mengajarkan kepadanya ilmu-ilmu syariah, ilmu alat, etika dan ilmu hadis. ${ }^{17}$ Maḥfuz al-Tarmasī memberikan ijazah kepada Hasyim Asy'arī untuk mengajar Șaḥịh al-Bukhārī. Maḥfuz al-Tarmasī juga dikenal sebagai ulama hadis Melayu

\footnotetext{
${ }^{16}$ Muhammad Mahfūż ibn Abdillah Muhammad Maḥfūż, Hāsyiyatu Al-Tarmas̄̄ alMusamma al-Manhal al-'Amìm bi Hāsyiyati alManhaj al-Qawìm wa Mauhibatu ż̀ al-Faḍl 'ala Syarhi al-Allāmah Ibnu Hajar (Jedah: Dār alManhal, 2011), 22.

${ }^{17}$ Syaikh Muhammad Hasyim Asy'arī alJunbany, Adab al-'Ilmī wa al-Muta' allim (Jombang: Maktabah at-Turāà al-Islāmī, 1415 H), 4.
} 
Indonesia melacak isnād (mata rantai hadis)-nya sampai kepada al-Sarqawi ${ }^{18}$

Dari berbagai cabang ilmu yang dikuasai oleh Syaikh Muḥammad Maḥfuz al-Tarmasī, bahwa ilmu hadislah yang menonjol dalam dirinya. Syaikh Yāsin bin Isā al-Fādānī dalam masalah ini menyebut Syaikh Maḥfuz al-Tarmasī dengan sematan al-Musnid al-Hāfiz. Yaitu seorang ulama yang ahli sanad dan hafal serta memahami banyak hadis. Gelar al-Hafiz ini adalah gelar tertinggi bagi orang yang hafal dan mendalami Hadis Nabawiyyah. ${ }^{19}$

Dari karya-karya Maḥfuz alTarmasī atas dapat disimpulkan bahwa Maḥfuz al-Tarmas̄i memiliki kapasitas keilmuwan juga intelektual di bidang qirā'at, ${ }^{20}$ dan hadis. Tetapi karya hadisnya lebih sedikit dari pada karyanya di bidang Alquran dan qirā'at.

\footnotetext{
${ }^{18}$ El-Saha, Intelektualisme, juz II, 108.

${ }^{19}$ Amiul Ulum, Ulama-Ulama Aswaja Nusantara yang Berpengarauh di Negeri Hijaz (Yogyakarta: Pustaka Ulama, 2015), 82.

${ }^{20}$ Selain dikenal sebagai pemberi ijazah hadis dan ilmu hadis, Syaikh Mahfuz at-Tarmasi juga dikenal sebagai maha guru qira'ah sab'ah, khususnya qira'ah riwayat Imam 'Așim. Sanad dan Ijazahnya pada para kiai, huffaz, dan Qurra di Jawa masih bias ditemukan sampai sekarang. Misalnya pada mata rantai sanad yang ada pada Pondok Pesantren Puteri Tahfiz Alquran al-Aziziyyah Bringin, Semarang. Dalam mata rantai sanad itu, Ibu Nyai Azizah al-Hafizah, pengasuh Pesantren menerima ijazah dari KH. Tirmizi Taslim Kauman Semarang dari KH. Muhammad ibn Syaikh Maḥfūz Muhammad Mạ̣fūż dan seterusnya sampai kepada Imam 'Așim dari Abd al-Rạ̣mān dari Us̀mān bin Affān dari Ubay ibn Ka'ab dari Muhammad Rasulullah saw.
}

Dalam pada itu tulisan artikel ini bermaksud ingin mengupas pemikiran dan kontribusi Mạ̣fūz al-Tarmas̄i dalam pengkajian hadis di Indonesia, penulis simpulkan mengenai kontribusinya.

1. Al-Minhah al-Khairiyyah yang berisikan 40 Hadis: Karya Hadis Perdananya $^{21}$

Sebagaimana kitab arba 'in lainnya, Maḥfüż al-Tarmasī menyusun hadis arba 'ìn yang kitabnya diberi judul dengan alMinhah al-Khairiyyah. Kemudian menyusun kitab syarah-nya ke dalam kitab khusus al-Khil'atu al-Fikriyyah Syarh alMinhatu al-Khairiyyah, yang kemudian menjadi karyanya yang kedua. Ia menghimpun empat puluh hadis pilihan dengan harapan mudah dihafalkan dan dipahami oleh umat.

Karyanya yang berjudul al-Minhah al-Khairiyyah merupakan karya beliau yang paling memasyarakat di kalangan pesantren. Ia menghimpun empat puluh hadis pilihan. Sebagaimana ulama sebelumnya yang telah melakukan hal yang sama, seperti Kitāb al-Arba'īn karya Abī Hasan Muḥammad ibn Aslam al-Ṭūsī (w. 242 H). Kemudian Kitāb al-Arba 'ìn karya al-Imām al-Hāfiz al-Qāsim ibn al-Faḍl al-

${ }^{21}$ Kitab berisi 22 hadis sulāsiyyyāt al-Bukhārī. Hadis Ślāsiyyāt adalah hadis yang antara periwayat sampai Rasulullah hanya terdapat tiga perawi, sehingga nilai kesahihannya sangat tinggi. 
Śaqafì al-Aṣbahān̄̄ (397-489 H). ${ }^{22}$ Imam alNawaw̄i mengarang kitab Arba'inn alNawawī. Muhammad Yāsin ibn Isa alFadānī juga yang mengumpulkan empat puluh hadis lengkap dengan sanadnya dari awal sampai akhir. Kemudian Syaikh Isma'īl 'Uṡmān al-Yaman̄̄ menghimpun empat puluh hadis yang diberi nama Arba 'ìn Hadīisan min Kalām Khair al-Anām fì al-Mawaiz wa al-Nașā'ị wa al-Ahkām.

Kemudian kitab Faid al-A 'lām fì Arba'ìn Hadìsan fì al-Salām. ${ }^{23}$

Keistimewaan kitab al-Minḥah alKhairiyyah fì Arba '̄in Hadīisan min Ahâadìs Khair al-Bariyyah karya Maḥfūẓ alTarmasī dibandingkan dengan kitab sejenis lainnya adalah bahwa kitab ini berisi 22 hadis Śsulāsiyyāt al-Bukhārī. Hadis Ślāsìyyāt al-Bukhārī adalah hadis yang antara periwayat sampai Rasulullah saw. Hanya terdapat tiga perawi. Jadi, dalam Sulāsiyyāt al-Bukhārī antara Imam alBukhārī sampai kepada Rasulullah saw. hanya terdapat tiga perawi saja, sehingga nilai kesahihannya sangat tinggi. Dalam pada itu jika ditilik dari kesahihan sanad dan matan, karya Syaikh Maḥfūz alTarmasī bisa dikatakan terdepan di antara karya-karya sejenis. Syaikh Mạ̣fūz al-

\footnotetext{
${ }^{22}$ Lihat Abī Hasan Muhammad ibn Aslam alṬūsīdan al-Imām al-Hāfiz al-Qāsim ibn al-Faḍl alŚ̉aqaīi al-Aṣbahānī. Kitāo al-Arba'īn (Beirūt: Dār Ibn Hazm, 2000).

${ }^{23}$ El-Saha, Intelektualisme, juz II, 109.
}

Tarmasī menerima sulāsiyyāt itu, sebagaimana ia kemukakan dalam mukaddimah-nya, dari gurunya yaitu Syaikh as-Sayyid Abū Bakar ibn as-Sayyid Muhammad Syațā. ${ }^{24}$ Kitab hadis ini sudah diterbitkan oleh Pondok Pesantren Betengan Demak atas prakarsa cucu pengarang yaitu, KH. Harir ibn Muhammad ibn Syaikh Maḥfuz al-Tarmasī dan telah beredar luas di seantero pesantren di Jawa. Dalam kata pengantarnya, KH. Maimun Zubair, Pengasuh Pondok Pesantren alAnwar, Sarang, menjuluki Syaikh Mạ̣fuẓ al-Tarmasī sebagai Syaikh al-Masyāyikh alA 'lām wa Qudwat al-Anām atau Maha gurunya para guru besar yang berilmu dan panutan manusia. Sebuah julukan yang wajar, sebab memang dari tangannya telah lahir puluhan ulama besar dan puluhan karya monumental. ${ }^{25}$

\section{Manhaj Żawī al-Nazar fì Syarh Manzumati 'Ilm al-'Asंar: Karya bidang Ilmu Muștalaḥ al-Ḥadīs}

Maḥfuz al-Tarmas̄̄ juga menuangkan kecerdasannya ke dalam beberapa karyanya yang lain, seperti Manhaj Żaw̄̄ al-Nazar fì Syarh Manẓumati 'Ilm al-'Asiar, Kifāyatu al-Mustafìd fimāa 'alā min al-Asānīd,. Karya Maḥfuz alTarmas̄̄ yang berjudul Manhaj Żawī al-

\footnotetext{
${ }^{24}$ El-Saha, Intelektualisme.

${ }^{25} \mathrm{El}-\mathrm{Saha}$, Intelektualisme.
} 
Naẓar fì Syarḥ Manẓumati 'Ilm al-'Aśar merupakan karya yang dijadikan referensi dibanyak Universitas seperti Mesir, Maroko, Mekah dan Indonesia. Karya yang satu ini merupakan kitab syarah dari karya besar ulama hadis dunia, yakni Alfiyyah alSuy $\bar{u} t \bar{l}^{26}$ yang membahas tentang ilmu hadis. Kesulitan dalam memahami nazmnaẓm yang terdapat dalam karya al-Suyūṭ̄, menjadikan Maḥfuz al-Tarmasī tertantang untuk kemudian mensyarahnya dengan maksud agar lebih mudah dipahami dan dimengerti para pelajar dan pecinta ilmu hadis pada umumnya. Karya tersebut merupakan puncak kreatifitas intelektualnya di bidang hadis, melebihi karya-karya sebelumnya. Kitab ini kemudian menjadi salah satu karya monumentalnya, yang pada akhirnya menghantarkan reputasi alTarmasī di kancah dunia sebagai seorang ulama Nusantara yang memiliki keahlian dalam bidang hadis.

Kitab yang berjudul Manhaj Żaw̄ al-Nazar fì Syarh Manẓumati 'Ilm al-'Aśar ini merupakan Syarah atau penjelasan atas kitab Manẓmati 'Ilm al-'Aśar dan

\footnotetext{
${ }^{26}$ Secara kronologis, kitab Alfiyyah al-Suyūțī yakni Manz̦umati 'Ilm al-'Asंar merupakan kitab yang sebanding dengan Alfiyyah al-Irāqi yakni alDurar fì 'Ilm al-Aśsar.Kitab al-'Irāqī sebelumnya sudah disyarah oleh al-Suyūțī dalam karyanya Qat' $u$ al-Durar. Kelihatannya al-Suyūțī kurang puas hanya dengan mensyarahnya, ia pun akhirnya terinspirasi untuk membuat alfiyyah serupa dengan apa yang dibuat seniornya al-Irāqī yang kemudian lebih dikenal dengan nama Alfiyyah al-Suyūți. Kitab inilah yang kemudian disyarah Mạ̣fūz Muhammad Maḥfüż dalam karya besanya Manhaj Żawī al-Nazar
}

diterbitkan pertama kalinya oleh percetakan Mustafa Bāb al-Halabī, sebuah percetakan tertua di kota Kairo, oleh beberapa guru besar ilmu Hadis Universitas al-Azhar dianggap sebagai kitab terbaik atas kitab Manẓumati 'Ilm al-'Asar. ${ }^{27}$ Kitab ini juga sudah tersebar di Haramain untuk kemudian dijadikan referensi ketika itu. ${ }^{28}$ Dari sinilah reputasi Maḥfuz al-Tarmasī mulai menyebar dalam skala internasional.

Maḥfūz al-Tarmasī dengan segala kemampuan intelektualnya mampu mensyarah secara lengkap karya al-Suyūṭī dalam bidang hadis. Sebuah reputasi yang tidak semua ulama mana pun mampu melakukannya. Dari karya inilah yang kemuadian membuat Mạ̣fūz al-Tarmasī mendapat julukan sebagai pembangkit ilmu dirayah hadìis. Kitabnya Manhaj Żawī alNazar fí Syarh Manzumati 'Ilm al- 'Aśar ini juga menjadi rujukan dan pegangan dalam memahami ilmu dirāyah ḥadīs.

Berdasarkan uraian di atas dapat dikatakan sumbangan terbesar Syaikh Muḥammad Maḥfūz al-Tarmasī terhadap kajian hadis di Indonesia khususnya dan juga dalam skala internasional pada umumnya, ialah usaha intelektualnya dalam menjelaskan kitab Alfiyyah al-Suyūțī yang

\footnotetext{
${ }^{27}$ El-Saha, Intelektualisme, juz II, 109.

${ }^{28}$ Muhyiddīn 'Ațiyyah, et al, Dalil Mu'allafāt al-Hadīs al-Nabawī al-Syarīf al-Mațū'ah alQadīmah wa al-Hadīisah (Beirūt: Dār Ibn Hazm, 1995), 69.
} 
ditulisnya dalam berbahasa Arab.Pada masa itu, yakni akhir abad-19, ada beberapa ulama dari Indonesia yang kepakaran dan keilmuannya di bidang agama diakui dunia Islam.Mereka diberi kesempatan seluasluasnya untuk mengajarkan ilmunya di Masjid al-Haram.

Muḥammad Maḥfūẓ ibn Abdillāh ibn Abd al-Mannān al-Tarmasī merupakan ulama Nusantara yang mendunia dan dikenal sebagai pembangkit ilmu dirayah hadis. Setidaknya ada tujuh ulama terkemuka yang dikenal luas, ${ }^{29}$ di antara mereka semua Maḥfūz al-Tarmasī yang memiliki karya fenomenal dalam kajian hadis yakni kitabnya Manhaj Żaw̄̄ al-Naẓar fì Syarh Manzumati 'Ilm al-'Aśar.Dapat dikatakan karyanya tersebut merupakan karya yang luar biasa dan terbaik pada zamannya. Salah satu karya monumentalnya di bidang hadis membuat Mạ̣fūz al-Tarmasī mendapat pembangkit ilmu dirayah hadis. ${ }^{30}$ Ketekunan beliau dan

\footnotetext{
${ }^{29}$ Mereka itu adalah Syaikh Mahfuz Muhammad Mạ̣füż (kelahiran Tremas, Pacitan), Syaikh Nawawi al-Bantani (kelahiran Banten), Syaikh Ahmad Khatib al-Minangkabawī, Syaikh Mukhtarom (kelahiran Banyumas), Syaikh Bakir (kelahiran Banyumas), Syaikh Asy'ar̄̄ (kelahiran Bawean) dan Syaikh 'Abd al-Hamid.

${ }^{30}$ Definisi lebih ringkas tentang Ilmu Hadis Dirāyah dikemukakan oleh M. 'Ajjāj al-Khațīb, sebagai berikut:

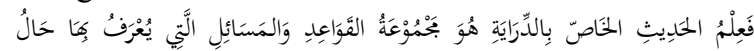

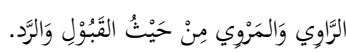

"Ilmu Hadis Dirāyah adalah kumpulan kaidahkaidah dan masalah-masalah untuk mengetahui keadaan rāwī (sanad) dan marwī (matan) untuk mengetahui apakah bisa diterima atau ditolak."
}

kealimannya membuat banyak ulama berbagai wilayah termasuk Nusantara berguru dan menuntut ilmu kepadanya. Oleh karena itu Maḥfūz al-Tarmasī sudah sepatutnya mendapat penghargaan yang selayaknya.

\section{Rantai Transmisi Sanad dalam kitab Kifāyatu al-Mustafìd fìmā 'alā min al- Asānīd}

Karya Maḥfūẓ al-Tarmas̄̄ yang berjudul Kifāyatu al-Mustafìd fìmā 'alā min al-Asānīd, sebuah kitab yang menggambarkan secara utuh transmisi transmisi keilmuan beliau selama 45 tahun mempelajari dan mendalami ilmu-ilmu agama baik di dalam negeri maupun di luar negeri khususnya di Haramain. Kitab Kifāyatu al-Mustafìd fimāa 'alā min alAsānīd sangat penting keberadaannya, karena sudah diteliti oleh seorang murid Maḥfūz al-Tarmasī yang bermukim di Makkah yaitu Syaikh Yāsin al-Fādānī. Kitab ini juga sudah diterbitkan oleh Dār alBasyā'ir Beirūt yang sudah di-tașḥihh, taḥqīq dan di-ta 'līq oleh Syaikh Yāsin. ${ }^{31}$

Adapun karya Mạ̣fūz al-Tarmasī yang bejudul Kifāyatu al-Mustafìd fimāa 'alā min al-Asānīd adalah sebuah karya yang tidak diragukan lagi. Otentitas karya ini sebagai hasil karya beliau yang didasari

\footnotetext{
${ }^{31}$ Muḥammad Maḥfūz ibn Abdillāh Muhammad Maḥfūż, Kifāyatu al-Mustafìd limā 'alā min al-Asānīd (t.t.: Dār al-Basyā'ir, t.th.), 41 .
} 
oleh naskah asli yang dimiliki Syaikh Abū al-Fayd Muḥammad Yāsīn bin 'Īsa alFādānī al-Makkī yang juga seorang ulama terkenal di Haramain asal Padang Sumatera Barat pada abad XX masehi. Bahkan Syaikh Yāsīn ini pada bagian akhir kitab Kifāyatu al-Mustafìd fimāa 'alā min alAsānīd menjelaskan bahwa Syaikh Muḥammad Maḥfūẓ al-Tarmasī merupakan Syaikh syuyūkhih (guru dari gurunya). ${ }^{32}$

Dalam karya beliau ini termuat lima disiplin keilmuan yang diuraikan transmisinya oleh Mạ̣fūz al-Tarmasī, yaitu: Ilmu tafsir, ilmu hadis, ilmu fikih, ilmu alat (ilmu nahwu dan saraf), ilmu dua uṣūl (ilmu kalam/tauhid dan ilmu saraf) dan ilmu tasawuf. Namun dalam artikel ini lebih difokuskan dalam bidang hadis. Transmisi keilmuan tersebut adalah kitab Șahīh alBukhārī, kitab Șah̄ị Muslim, Sunan Abi Dawud, Sunan al-Tirmiż̄i, Sunan al-Nasā' '̄, Sunan Ibn Mājah, Muwatta' Mālik, Musnad al-Syāfi ‘’̄, Musnad Abī Hanifah, Musnad Ahmad ibn Hanbal, Mukhtașar ibn Abì Hamzah, Kitāb al-Syifā', Kitāb al-Arba'īn al-Nawawiyyah. Kitāb Syamā'il karya alTirmiżī, Kitab al-Sirah al-Halabiyah.

Sebagai contoh transmisi dan jaringan ulama Maḥfūz al-Tarmas̄̄ terhadap kitab Ṣah̄ị al-Bukhārī, yaitu; Syaikh Maḥfüż al-Tarmas̄i meriwayatkannya secara $\operatorname{sim}^{\star}{ }^{\star}$ berkali-kali (empat kali

\footnotetext{
${ }^{32}$ Maḥfüż, Kifāyatu, 41.
}

khatam), dari Syaikh Sayyid Abū Bakr ibn Muḥammad Syațā al-Makkī, dari Sayyid Aḥmad ibn Zain̄̄ Dahlan dari Syaikh 'Usmān ibn Hasan al-Dimyāṭ̄ dari Syaikh Muḥammad ibn 'Alī al-Syinwanī dari 'Īsā ibn Aḥmad al-Barawi dari Syaikh Muhammad al-Dafrī dari Syaikh Sālim ibn Abdillāh al-Baṣrī dari Syaikh Muḥammad ibn Alauddīn al-Babili dari Syaikh Sālim ibn Muḥammad al-Sanhūrī dari Najm Muḥammad ibn Aḥmad al-Ghaiṭ̂̄ dari Syaikh Islam Zakariyya ibn Muhammad alAnșārī dari al-Ḥāfiẓ Aḥmad ibn 'Ālī ibn Ḥajar al-‘Asqalānī (w. 852 H) dari Ibrāhim ibn Aḥmad al-Tahānuwī (w. 800 H) dari Abū al-Abbās Aḥmad ibn Abū Ṭālib alHajjār (w. 733 H) dari al-Ḥusyain ibn alMubārak al-Zabīdī al-Hanbalī (w. $631 \mathrm{H}$ ) dari Abū al-Waqt 'Abd al-Awwāl ibn 'Īsā as-Sijzī dari Abū al-Ḥasan 'Abd al-Raḥmān ibn Muzaffar ibn Dāwūd ad-Dāwūdī dari Abū Muḥammad 'Abdullāh ibn Aḥmad alSarkhasī dari Abū 'Abdillāh Muḥammad ibn Yūsuf ibn Mațar al-Firabrī (w. 320 H) dari al-Imām al-Ḥāfiz al-Hujjah Abū 'Abdillāh Muḥammad ibn Ismā'îl ibn Ibrāhīm ibn Ibrāhīm al-Bukhārī (w. 256 H). ${ }^{33}$

Dari uraian contoh transmisi kitab Sahịh al-Bukhārī, sangat jelas jaringan keilmuan ulama yang terbangun melalui silsilah keguruan ini. Bila ditelusuri guru-

\footnotetext{
${ }^{33}$ Maḥūż, Kifāyatu, 15.
} 
guru Syaikh Mạ̣fūż al-Tarmasī berasal dari berbagai belahan dunia Islam, dalam hal itu mencerminkan keluasan ilmu dan jaringan sekaligus.

\section{Kesimpulan}

Dapat dikatakan bahwa kontribusi pemikiran Maḥfūẓ al-Tarmas̄i dalam pengkajian Hadis di Indonesia dapat dilihat dalam kitab, pertama; Al-Minḥah alKhairiyyah. Kedua, Manhaj Żawī al-Naẓar fì Syarh Manzūmati 'Ilm al-'Aśar. Ketiga, Transmisi sanad dalam kitab yang berjudul Kifāyatu al-Mustafìd fìmā 'alā min alAsānīd karya Muḥammad Yāsin al-Fādān̄̄.

Karya Maḥfuz al-Tarmasī yang berjudul Manhaj Żawī al-Nazar fì Syarh Manzumati 'Ilm al-'Asar merupakan karya yang dijadikan referensi dibanyak Universitas seperti Mesir, Maroko, Mekah dan Indonesia. Karya yang satu ini merupakan kitab syarah dari karya besar ulama hadis dunia, yakni Alfiyyah al-Suyūțī yang membahas tentang ilmu hadis. Kesulitan dalam memahami naẓm-naẓm yang terdapat dalam karya al-Suyūṭi, menjadikan Maḥuz al-Tarmasī tertantang untuk kemudian mensyarahnya dengan maksud agar lebih mudah dipahami dan dimengerti para pelajar dan pecinta ilmu hadis pada umumnya. Karya tersebut merupakan puncak kreatifitas intelektualnya di bidang hadis, melebihi karya-karya sebelumnya. Kitab ini kemudian menjadi salah satu karya monumentalnya, yang pada akhirnya menghantarkan reputasi alTarmas̄̄ di kancah dunia sebagai seorang ulama Nusantara yang memiliki keahlian dalam bidang hadis.

\section{Daftar Pustaka}

al-Aṣbahānī. Abī Ḥasan Muḥammad ibn Aslam al-Ṭūsīdan al-Imām al-Ḥāiụ al-Qāsim ibn alFaụl al-Ṡaqafì. Kitāb al-Arba īn. Beirūt: Dār Ibn Hazm, 2000.

'Ațiyyah, Muhyiddīn, et al. Dalil Mu'allafāt al-Hadīis an-Nabawī al-Syarīf al-Maṭbū'ah alQadìmah wa al-Hadīsah. Beirūt: Dār Ibn Ḥazm, 1995.

Azra, Azyumardi. Jaringan Ulama Timur Tengah dan Kepulauan Nusantara Abad XVII \& $X V I I I$ H. t.t.: t.p, t.th.

El-Saha, Matsuki \& M Ishom. Intelektualisme Pesantren Potret Tokoh dan Cakrawala Pemikiran di Era Pertumbuhan Pesantren. Jakarta: Diva Pustaka, 2003. 
al-Junbany, Syaikh Muhammad Hasyim Asy'arī. Adab al-'Ilmī wa al-Muta 'allim. Jombang: Maktabah at-Turās̀ al-Islāmī, 1415 H.

al-Marṣafī, Abd al-Fattāḥ Sayyid al-Ajamī. Hidāyatu al-Qārī ilā Tajwìd Kalām al-Bārī. AlMadinatu al-Munawwarah: Maktabah Tibah, t.th.

Mas'ud, Abdurrahman. Dari Haramain ke Nusantara, Jejak Intelektual Arsitek Pesantren. Jakarta: Kencana Media Group, 2006.

al-Mu'allimī, 'Abd al-Raḥmān ibn 'Abd ar-Raḥīm. A 'lām al-Makkiyyīn min al-Qarn al-Tāsi' ila Qarni ar-Rābi ‘ 'Asyar al-Hijrī. Mekah: Mu'assasah al-Furqān li Turās̀ al-Islāmī, 2000.

al-Tarmasī, Muhammad Maḥfüż ibn Abdillah. Hạsyiyatu al-Tarmasī a-Musamma al-Manhal al-'Amìm bi Hāsyiyati al-Manhaj al-Qawìm wa Mauhibatu ż̀ al-Fạ̣l 'ala Syarhi alAllāmah Ibnu Hajar. Jedah: Dār al-Manhal, 2011. - Kifāyatu al-Mustafid limā 'Alā min al-Asānid. Saudi: Dar al-Basya'iri alIslāmiyyah, t.th.

Ulum, Amiul. Ulama-Ulama Aswaja Nusantara yang Berpengarauh di Negeri Hijaz. Yogyakarta: Pustaka Ulama, 2015.

Yaqub, Ali Mustafa. Islam Masa Kini. Jakarta: Pustaka Firdaus, 2001 
KONTRIBUSI MAHFŪZZ AL-TARMASİ DALAM PENGKAJIAN HADIS DI INDONESIA 